\title{
MONTHLY PROGRESS REPORT
}

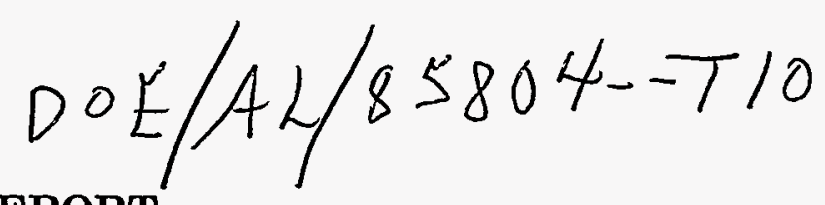

\author{
Hydrogen from Renewable Resources \\ University of Hawaii \\ Grant No. DE-FG36-94AL85804
}

February 1996

\section{TASK 1. HYDROGEN PRODUCTION}

\section{Subtask 1A. Thermochemical Production of Hydrogen from Wet Biomass - M. J. Antal}

This month, further progress in the design and fabrication of the new reactor/feeder was achieved. High-pressure gas separation was explored further, and some supplemental experiments on activated carbon production and carbon gasification characteristics in supercritical water were carried out.

\section{New Reactor/Feeding System Design}

As a first step in scaling up the reactor size for hydrogen production, a reactor/feeder system was designed for rapid mixing of biomass paste with supercritical water using a large size tubing instead of a pipe. High concentration biomass paste flows inside a stainless steel tube connected to the feeder. The biomass feedstock mixes with a stream of water at elevated temperature and pressure, and then flows into a reactor packed with carbon catalyst where the temperature is maintained at $600^{\circ} \mathrm{C}$ for gasification. The piston feeder will arrive in the middle of March. Heaters, Swagelok fittings, and stainless steel tubing have been received and the system is now being assembled.

\section{Gasification process}

This month, an estimation of the effect of high-pressure carbon dioxide separation was improved, and energy flow analysis for an ideal system was conducted. Binary interaction parameters for the SRK equation were re-determined based on the least square fitting technique. The program was extended so that it can deal with all four components, therefore allowing the estimation of carbon monoxide behavior in addition to water, carbon dioxide, and hydrogen. Good agreement was obtained between calculation and experiment for not only the hydrogen - carbon dioxide ratio but also the composition of product gas mixtures for different operating pressures. An energy flow diagram of the supercritical water gasification process was drawn using this high-pressure separation system. The efficiency of the heat exchanger to recover heat from the reactor effluent by heating up the feed influences the system efficiency significantly. These results will be presented at the Developments in Thermochemical Biomass Conversion Conference in Banff.

Two experiments involving activated carbon production from high-yield macadamia nut charcoal were conducted. These experiments provide us with samples for surface area analysis to evaluate the characteristics of activated carbon produced by supercritical water treatment, which may be used as a gasification catalyst. Longer experiments on activated carbon behavior in supercritical water were also carried out. Coconut shell activated carbon was treated in supercritical 
water at $650^{\circ} \mathrm{C}, 34.5 \mathrm{MPa}$ for three days at 6 hours a day. Samples at conversions of $35 \%$ and $50 \%$ were taken for surface area analysis. These results will verify the effectiveness of the gasification rate equation proposed previously in the range of high conversions.

\section{Future work}

In March, the reactor/feeder system will be assembled. A supporting structure will also be constructed. A literature survey on the shift reaction will be also conducted. Increases in hydrogen yields will be the next target.

Subtask 1B. Photoelectrochemical Hydrogen Production - R. E. Rocheleau

Last month we reported long term stability testing of oxygen and hydrogen catalysts. Both catalyst were shown to perform well without any degradation for the entire length of the testing period (more than 140 hours). In the month of February, we took the next step in performance testing, characterization of complete photoelectrodes and cells in terms of their stability and efficiency. In the beginning of the month, a new batch of individual triple junction solar cells each with an active area of $0.27 \mathrm{~cm}^{2}$ were cut from a sheet of cells. These cells were then mounted on the electrochemical cell by directly pressing the hydrogen catalyst (CoMo) to the back of the solar cell (n-layer) and connecting the p-layer to the $\mathrm{NiFeO}_{\mathrm{x}}$ oxygen catalyst through an external circuit as shown in Figure 1.
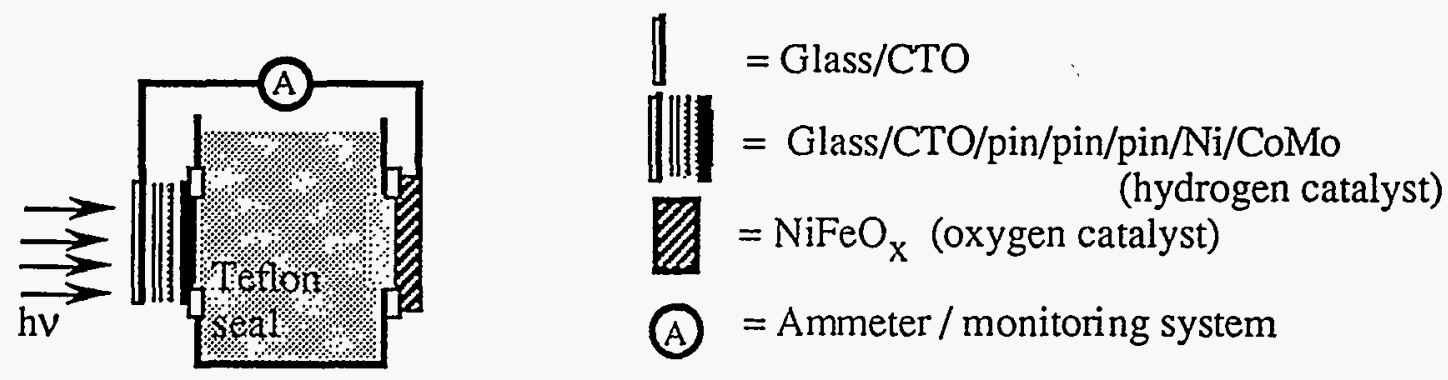

Fig. 1: Schematic of $\mathrm{H}_{2}$ photoelectrolysis cells using multijunction a-Si:H photoelectrodes.

Testing of the PEC cell for stability and gas production was conducted indoors using an ELH bulb. Figure 2 shows the cumulative hydrogen and oxygen collection over a period of 144 hours for a $0.27 \mathrm{~cm}^{2}$ photoelectrode operating at a current density of $6.5 \mathrm{~mA} / \mathrm{cm}^{2}$ (approximately one sun). The theoretical yields of hydrogen and oxygen, assuming $100 \%$ of the measured anodic-cathodic current results in $\mathrm{H}_{2} / \mathrm{O}_{2}$ production, are also shown. As shown in the figure, the hydrogen and oxygen production rates are constant over time, indicating stability of both catalysts and the photodiode. We believe that the difference between the actual gas collection and that expected based on the current between the anode and cathode surfaces is due to dissolution of gas into the $\mathrm{KOH}$ solution with subsequent reaction in solution or 
release into the air from the open system. These tests were conducted at low current levels without a gas separation membrane in the cell. Similar tests, using the same catalysts and similar photoelectrode structures, in reactors with different geometries and/or at higher current densities yielded gas collection efficiencies up to $95 \%$ of the expected value. Design and fabrication of new enclosed cell to improve gas collection efficiency using recirculating electrolyte is planned for the near future. This cell will be fully integrated eliminating the use of an external lead from the p-layer to the anodic catalysts. Experiments will also be designed to identify the variables which affect the gas collection efficiency.

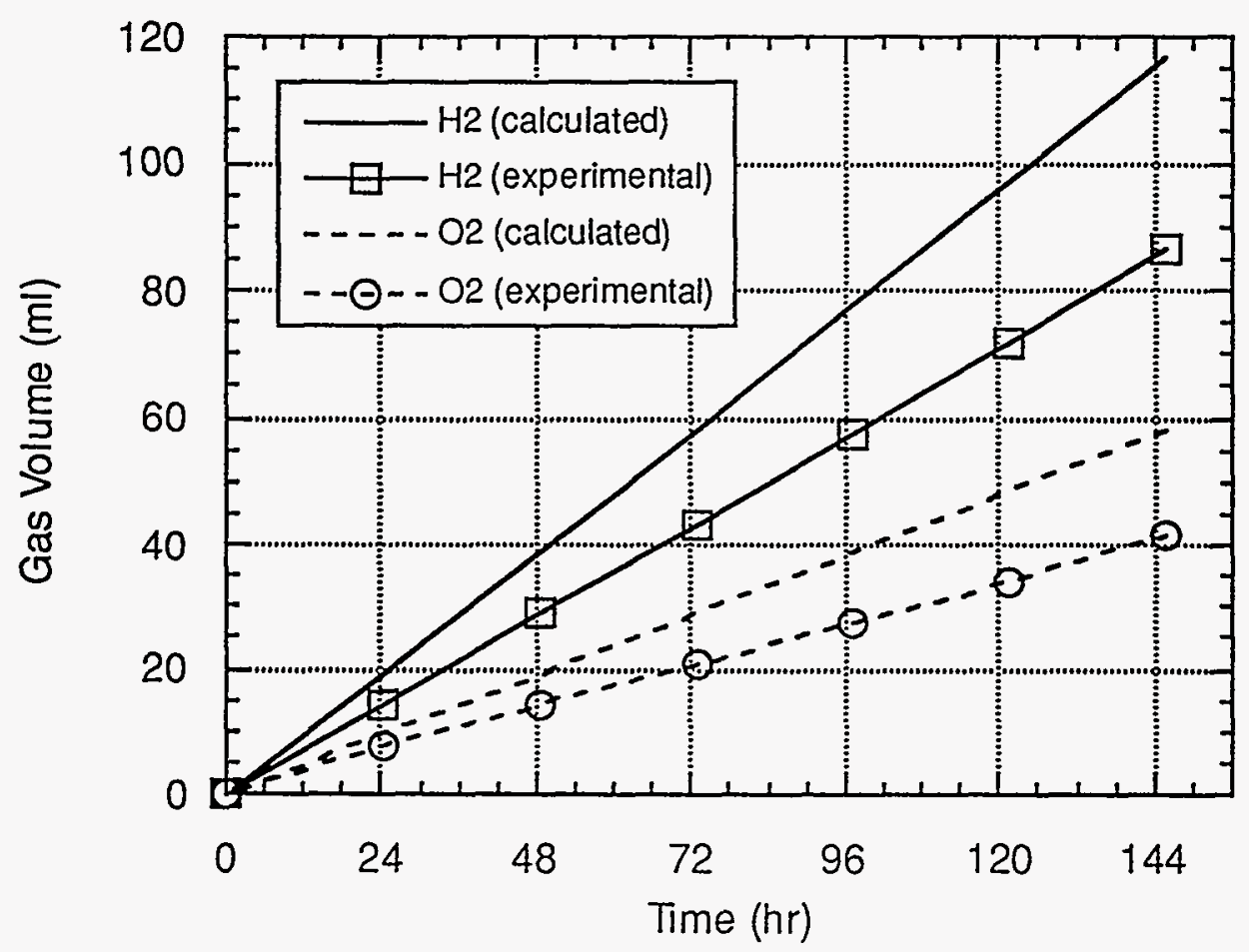

Fig. 2: Cumulative $\mathrm{H}_{2}$ and $\mathrm{O}_{2}$ production from a-Si:H multijunction photoelectrode under constant illumination. Experimental line based on actual gas collection. Theoretical line calculated from measured anodic-cathodic current.

Because of the mismatch between the spectra of the ELH lamp and the absorption characteristics of the triple junction cell which was optimized for natural sunlight, efficiency testing was conducted outdoors for greater accuracy. Outdoor efficiency testing was conducted by tilting the photoreactor (Figure 1) toward the sun. An external aperture was added to insure against light-piping through the edges of the photoelectrode. A standard crystalline silicon cell (pn junction), mounted onto the reactor in the same plane as the photoelectrode, was used to monitor the insolation. The $0.9 \mathrm{~cm}^{2}$ crystalline cell, calibrated under ELH light at the Institute of Energy Conversion, University of Delaware exhibits a short circuit current density of 24.25 $\mathrm{mA} / \mathrm{cm}^{2}$ at $100 \mathrm{~mW} / \mathrm{cm}^{2}$. The current density is directly proportional to light 
intensity over the range of interest. Current densities under natural solar radiation could be different by as much as $5 \%$.

Figure 3 shows the results of a two hour outdoor test. The line shows the insolation as a function of time (right ordinate) assuming $100 \mathrm{~mW} / \mathrm{cm}^{2}$ incident radiation at a short circuit current density of $24.25 \mathrm{~mA} / \mathrm{cm}^{2}$ in the silicon cell. The considerable variability with time is attributable to passing clouds on the day of the test. The symbols (left ordinate) show the measured current between the anodic and cathodic surfaces of the photoelectrode. The inset at the top of figure 3 shows the net conversion efficiency of the photoelectrode as a function of time assuming $100 \%$ reaction efficiency calculated according to:

where

$$
\mathrm{Eff}=(\mathrm{J} \times 1.23) /\left(\mathrm{P}_{\mathrm{in}}\right)
$$

$J=$ measured operating current of the photoelectrochemical cell $\left(\mathrm{mA} / \mathrm{cm}^{2}\right)$

1.23 = thermodynamic potential for water splitting $(V)$

$\mathrm{P}_{\mathrm{in}}=$ insolation determined from $\mathrm{Jsc}$ of the silicon cell $\left(\mathrm{mW} / \mathrm{cm}^{2}\right)$

The hydrogen production efficiency was essentially constant at $7.5 \%$ although the insolation varied from a high of $130 \mathrm{~mW} / \mathrm{cm}^{2}$ to a low of $30 \mathrm{~mW} / \mathrm{cm}^{2}$ during the test. Although hydrogen was collected during this test, the small photoelectrode area and relatively short test made quantification difficult. Outdoor testing with gas collection is planned with the new cell with circulating electrolyte.

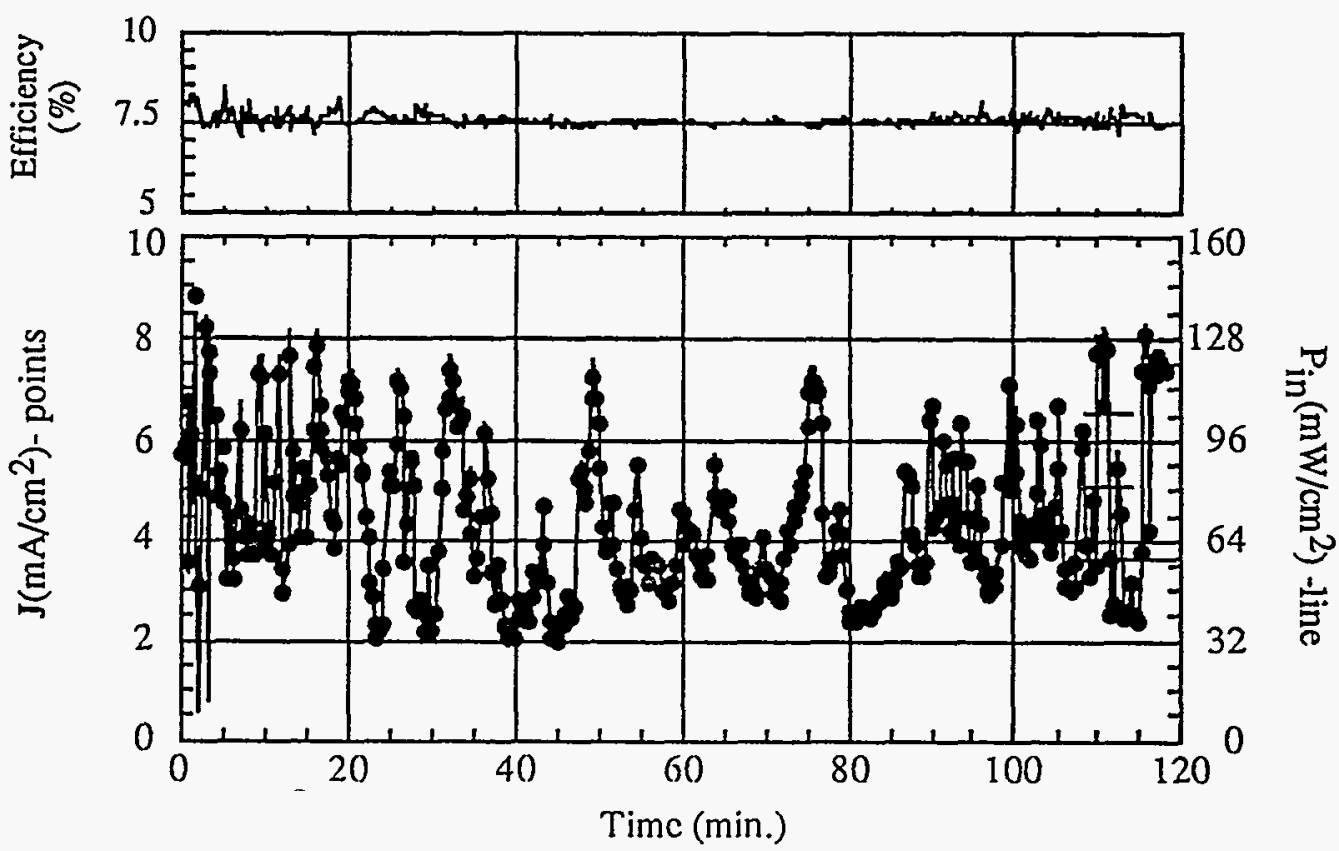

Fig. 3: Conversion efficiency and photoelectrode current density (points) during a 2 hour outdoor test (insolation shown by line). 
Subtask 1C. Photobiological Production - O. Zaborsky, K. Baker, D. Borthakur

Progress was made in several areas regarding the culture collection: transfer of the cyanobacterial cultures presently in Hawaii, changing the listing process of organisms imported through the Plant Quarantine Branch, approval for importation of the standard strain Rhodobacter sphaeroides, interaction continuing on an international level, ordering of major items of equipment, and further genetic research.

The cyanobacterial strains (from one of three triplicate sets of test tubes and vials) exhibiting obvious growth (146 of the 160 cultures actually imported) were transferred into media used in Professor Mitsui's laboratory (A-N and 1/0th A) in liquid and/or agar cultures. Growth conditions were modified to promote higher growth rates including less culture media per transfer (decrease in lag phase), and higher light conditions. Visually the growth has dramatically increased and 145 of the cultures transferred have obvious growth, a high rate of success. Information on the transfer and growth was documented on the computer.

Progress was made in several areas with interaction with quarantine restrictions. An amended import permit was obtained allowing for the importation of the standard strain of purple nonsulfur bacteria from Japan, Rhodobacter sphaeroides. This amendment was made possible by the verification of published documentation of the newly formed genus Rhodobacter and the transfer of the species Rhodopseudomonas sphaeroides to this newly formed genus. The genus Rhodopseudomonas had been listed on a prior permit allowing importation of strains of this genus into the Bioresources Laboratory. In addition, the Senate Bill 2682 S.D. Relating to Plant and Nondomestic Animal Quarantine (introduced by the State of Hawaii Department of Agriculture, Plant Quarantine Branch to the state legislature to expedite the importation of strains from unlisted genera) was passed by the Senate Committee on Agriculture and Labor. Information was presented in support of the bill by Brian Nakamura and Dr. Baker to the Senate Committee on Ways and Means. The bill is presently going through committees in the House.

Interaction continued internationally, including visits to the Bioresources Laboratory by Catherine E. Gregoire Padro (Hydrogen Program Manager, National Renewable Energy Laboratory) providing an update on progress with the International Marine Biotechnology Culture Collection and the Bioresoures Laboratory and Toshi Tsuzuki (Showa Denko K.K., Central Research Lab., Chiba, Japan) who was traveling from the University of Miami to Japan provided information on the remaining documentation in Miami on the collection. Ten boxes giving pertinent information such as strain renumbering on the purple nonsulfur bacteria remain in Miami. Technical information exchange continues with several researchers including Dr. Hisato Ikemoto (Marine Biological Institute, Kamaishi Japan) on natural seawater media alternative to Dr. Mitsui's media and strains in the collection that may contain polysaccharide producing compounds and Dr. Noriyuki Nakamura (Tokyo University of Agriculture and Technology, Tokyo) on media appropriate for the purple nonsulfur bacteria. The goal is to simplify the media preparation to incorporate more strains from more taxa with less media preparation time. 
Equipment ordered included an ultralow freezer (Revco $-86^{\circ} \mathrm{C}$ ), a Virtis Sonic Dismembrator, and a FotoPrep Camera and Mluminator for genetic characterization through the School for Ocean and Earth Science and Technology.

Under separate funding (Japanese matching funds) we are working to develop an easy and quick method of screening cyanobacterial strains for hydrogenase activity. We recently focused our attention on four hox genes involved in the synthesis of a bidirectional hydrogenase in cyanobacteria. These genes have been recently cloned and characterized in the laboratory of Dr. H. Bothe in Germany. The presence of this hydrogenase is a good indication of a strain's ability to produce hydrogen. Therefore, we made a set of three pairs of primers based on the published DNA sequences of these genes. We tested these primers in amplifying the hox genes of Anabaena strain 7120 DNA using polymerase chain reaction. Two pairs of these primers generated the DNA fragments of expected size with the Anabaena DNA as the template. We are now ready to test these primers on additional cyanobacterial strains..

\section{DISCLAIMER}

This report was prepared as an account of work sponsored by an agency of the United States Government. Neither the United States Government nor any agency thereof, nor any of their employees, makes any warranty, express or implied, or assumes any legal liability or responsibility for the accuracy, completeness, or usefulness of any information, apparatus, product, or process disclosed, or represents that its use would not infringe privately owned rights. Reference herein to any specific commercial product, process, or service by trade name, trademark, manufacturer, or otherwise does not necessarily constitute or imply its endorsement, recommendation, or favoring by the United States Government or any agency thereof. The views and opinions of authors expressed herein do not necessarily state or reflect those of the United States Government or any agency thereof. 


\section{TASK 2. HYDROGEN STORAGE}

\section{Subtask 2A. Reversible Catalytic Dehydrogenation of Cycloalkanes by Polyhydride Complexes - C. Jensen}

We have continued our studies of catalytic alkane dehydrogenation by complexes containing chelating, metallated bisphosphine ligands. Our studies have shown that such complexes have very pronounced thermal stabilities. During the past month, we have prepared the dihydride complex, \{2,6-Bis[(di-tert-butylphosphino)methyl]phenyl)- dihydridorhodium (seen below) from the corresponding hydridochloride complex.

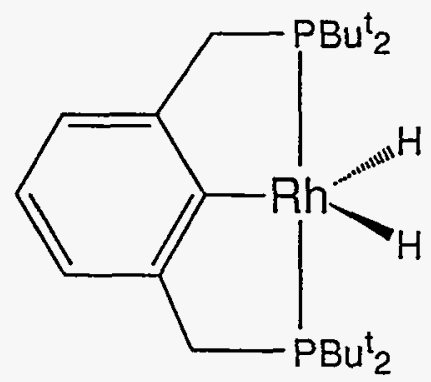

We have found that the dihydride complex is an active catalyst for alkane dehydrogenation. At $150{ }^{\circ} \mathrm{C}$, the complex catalyzes alkane dehydrogenation at a rate comparable to $\mathrm{RhCl}\left(\mathrm{PPh}_{3}\right)_{3}$ (Wilkinson's catalyst) which is among the best previously reported alkane dehydrogenation catalysts. However, unlike Wilkinson's catalyst which has a short (ca $12 \mathrm{~h}$ ) half life at the reaction temperature, our dihydride catalyst shows no sign of decomposition at $150^{\circ} \mathrm{C}$ after reactions times as long as $120 \mathrm{~h}$. Thus we have already achieved an eight fold improvement in the total number of catalytic turnovers which can be obtained. In order to determine if our catalyst is indefinitely stable at $150{ }^{\circ} \mathrm{C}$, longer term experiments are presently in progress. We are also exploring reaction rates and stability of our catalyst at $200^{\circ} \mathrm{C}$. A preliminary experiment has shown there is at least a five fold improvement in the catalytic rate at this temperature.

Subtask 2B. Thermodynamic Characterization \& Engineering - R. Rocheleau \& R. Zidan

During February, the investigation of the Triphenylphosphine-Cu complex which had shown promise during testing of small samples in January was continued. A new $5 \mathrm{~g}$ sample, obtained from Aldrich, was divided into $1 \mathrm{~g}$ and $0.5 \mathrm{~g}$ samples for testing. A 1 g sample, loaded into the characterization apparatus under argon atmosphere, was tested for hydrogen uptake at a number of different temperatures. Preliminary tests were conducted using sudden pressurization with a subsequent drop indicative of hydrogen uptake. After taking into account the temporary change of temperature due to fast pressurization, the expected drop in pressure was not observed. Similarly, when tested for hydrogen release, using sudden depressurization, no 
pressure rise was detected. The above tests were repeated on two other samples of 1 $\mathrm{g}$ and $0.5 \mathrm{~g}$ of the $\mathrm{Cu}$-complex with the same results were obtained.

Adiabatic measurements were then conducted to determine if hydrogen absorption or desorption could be observed during slow pressurization or depressurization. Again, no uptake or release of hydrogen was observed, in sharp contrast to the results of earlier testing in which uptake and release was observed for many cycles with smaller sample. Although no direct evidence is yet available, we believe the differences in behavior may be attributable to differences in the quality and properties of the samples. The appearance, color and mesh of the second sample was a observed to be different than the first. An Aldrich representative was contacted to request another sample and to discuss possible variations between samples. We learned that the current samples of the Cu-complex are only $90 \%$ pure and there is little control of the contaminants or even information on what contaminants are present. During the next month, we will attempt to characterize the contaminants in the different batches of sample, and will discuss with Dr. Jensen the possibility of inhouse synthesis of higher purity samples of this material than can be obtained commercially.

One of the important aspects of measuring hydrogen in these complexes is to be able to distinguish small amounts of hydrogen being dissolved in the complex over a wide range of pressure. In an effort to improve the accuracy of our readings and to distinguish readings from noise, especially during fast hydrogenation and dehydrogenation of samples, we are currently working on implementing a 20-bit $\mathrm{A} / \mathrm{D}$ converter which will also allow high speed data collection, up to 100 readings per second. We are currently requesting information on and evaluating different $\mathrm{A} / \mathrm{D}$ converters for these purpose.

During March we intend to test several new cobalt-based complexes that have ligand structures similar to the Ir-complex for which we previously reported reproducible hydrogen uptake and release. Further evaluation of the behavior of the Cu-complex will be conducted in an effort to distinguish the differences between samples. The data acquisition system will be modified for higher precision. 